\section{$\underset{\substack{\text { hommes } \\ \text { \& migrations }}}{ }$}

\section{Hommes \& migrations}

Revue française de référence sur les dynamiques

migratoires

1277 | 2009

France - Allemagne

\title{
L'Allemagne et la France en miroir
}

\section{Marie Poinsot}

\section{(2) OpenEdition \\ Journals}

\section{Édition électronique}

URL : http://journals.openedition.org/hommesmigrations/148

DOI : 10.4000/hommesmigrations. 148

ISSN : 2262-3353

\section{Éditeur}

Musée national de l'histoire de l'immigration

\section{Édition imprimée}

Date de publication : 1 janvier 2009

Pagination : 1

ISSN : 1142-852X

\section{Référence électronique}

Marie Poinsot, «L'Allemagne et la France en miroir », Hommes \& migrations [En ligne], 1277 | 2009, mis en ligne le 29 mai 2013, consulté le 22 septembre 2020. URL : http://journals.openedition.org/ hommesmigrations/148; DOl : https://doi.org/10.4000/hommesmigrations.148 


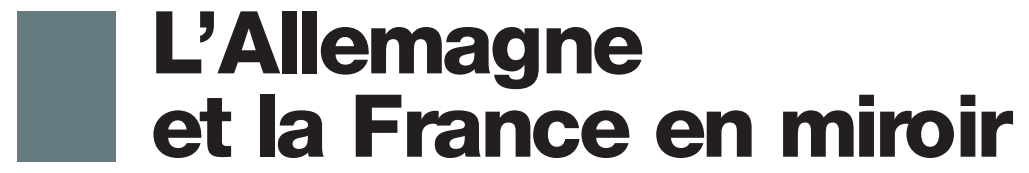

Par Marie Poinsot, rédactrice en chef

Si la France et l'Allemagne apparaissent comme les deux principaux pays d'immigration en Europe, leurs attitudes face aux enjeux associés aux migrations divergent sur certains points. Depuis les années 1980, la France mène une politique d'immigration restrictive, a mis en place des outils d'intégration en direction des nouveaux arrivants en situation régulière et questionne son modèle d'intégration républicaine. Pendant ce temps, l'Allemagne a accueilli depuis la chute du mur de Berlin plusieurs millions d'étrangers et d'Aussiedler, elle a réformé son droit de la nationalité pour introduire enfin le jus soli et conduit une politique d'immigration sélective en fonction des besoins de son économie.

Dans ce cadre général, le dossier d'Hommes \& Migrations apporte des éclairages et des analyses principalement sur la situation de l'Allemagne. Car la connaissance réciproque des réalités de part et d'autre de la frontière reste trop souvent limitée, y compris au sein de la recherche en science sociale. La rédaction espère ainsi fournir des éléments permettant de réfléchir à la manière dont l'Allemagne apporte des réponses parfois différentes à des questions qui se posent également en France dans ce domaine. À partir de ce constat, est-il encore pertinent de penser que le couple franco-allemand peut jouer un rôle moteur dans la construction d'une politique d'immigration européenne ? Les conséquences de la crise économique actuelle vont-elles modifier drastiquement les attitudes que ces deux pays ont adoptées face à l'immigration?

Rassemblés par Catherine Wihtol de Wenden (CERI), les articles du dossier sont en partie issus du colloque organisé par la Cité nationale de l'histoire de l'immigration en novembre 2007 qui avait réuni à Strasbourg plus d'une trentaine de chercheurs français et allemands spécialisés sur cette même problématique. Mais, compte tenu de l'ampleur du domaine abordé, la rédaction a voulu limiter le champ de la comparaison à deux enjeux qui traversent l'Allemagne et la France avec plus ou moins de vigueur : l'évolution des politiques d'immigration - faut-il limiter, accroître, contrôler ou expulser les étrangers ? -, et le débat sur les identités nationales et la citoyenneté - naturalisation, double nationalité, multiculturalisme, rapports aux autres, participation démocratique.

Ce dossier s'inscrit également dans le prolongement de l'exposition "À̀ chacun ses étrangers ? France-Allemagne de 1871 à aujourd'hui", réalisée par la CNHI en partenariat avec le Deutsches Historisches Museum de Berlin. Cette exposition traite de l'histoire des représentations des étrangers dans les deux pays en comparant les images construites dans l'espace public par les discours politiques, les administrations, les médias et les arts pour signifier qui est l'autre (le migrant, l'étranger, le colonisé, etc.) et comment il apparaît dans le processus de fabrication des sociétés contemporaines. Cette exposition compare également les évolutions de ces représentations selon les contextes économiques, sociaux et politiques qui ont fortement marqué, parfois avec des chronologies différentes, les deux histoires nationales. 